\title{
An Amperometric Glucose Biosensor Based on Titania Sol-gel/Prussian Blue Composite Film
}

\author{
Ruping LIANG, ${ }^{\dagger}$ Jingli Jiang, and Jianding QIU \\ Department of Chemistry, Nanchang University, Nanchang 330031, China
}

\begin{abstract}
An improved amperometric glucose biosensor was constructed by immobilizing glucose oxidase (GOD) in a titania sol-gel film, which was prepared by a vapor deposition method, on a Prussian Blue (PB)-modified electrode. The method combined the merits of immobilizing biomolecules in the titania sol-gel film by vapor deposition method and the synergic catalysis effects of PB and GOD molecules. Results showed that the fabricated titania sol-gel/PB membrane possessed high surface area, good mechanical stability, and good hydrophilicity, which provided a biocompatible microenvironment for maintaining the bioactivity of the immobilized enzyme and prevented the enzyme from leaking out of the film. Therefore, the present biosensor exhibited fast response time $(10 \mathrm{~s})$, high sensitivity $\left(12.74 \mu \mathrm{A} \mathrm{cm}^{-2} \mathrm{mM}^{-1}\right)$, long-term operational stability, good suppression of interference, and a wide linear range from 0.02 to $15 \mathrm{mM}$ with a low detection limit of $5 \mu \mathrm{M}$ for the detection of glucose. In addition, this simple and controllable method could fabricate biosensors in batches with a very small amount of enzyme.
\end{abstract}

(Received October 16, 2007; Accepted May 12, 2008; Published November 10, 2008)

\section{Introduction}

Enzyme-based biosensors integrating enzyme components and transducers have been widely applied in chemistry and biology due to their high sensitivity and selectivity, ${ }^{1-9}$ in addition to low cost and possibility of miniaturization/automation. Among the enzyme-based biosensors, considerable efforts have been devoted to the search for reliable glucose sensors owing to their usefulness in the diagnostic analysis of diabetes. ${ }^{10}$ The glucose oxidase (GOD) catalyzes glucose oxidation in the presence of molecular oxygen to form $\mathrm{H}_{2} \mathrm{O}_{2}$, which can be monitored electrochemically during the course of the reaction.

In order to realize electrochemical monitoring of the enzymatic reaction product, enzymes are usually immobilized on electrode surfaces by physical adsorption, solvent casting, and covalent binding, electropolymerization, or LangmuirBlodgett deposition methods. ${ }^{11}$ In recent years, silica sol-gel material as one matrix has attracted attention because of its suitability for the immobilization of enzymes ${ }^{12,13}$ and for the construction of $\mathrm{H}_{2} \mathrm{O}_{2}$ biosensors. ${ }^{14,15}$ This kind of inorganic silica sol-gel material can be prepared under ambient conditions and exhibits tunable porosity, high thermal stability, chemical inertness and negligible swelling in both aqueous and nonaqueous solutions. ${ }^{16-18}$ It is biocompatible and can retain the catalytic activities of enzymes to a large extent. ${ }^{19-21}$ However, the silica sol-gel matrices also have some obvious shortcomings, such as fragility, hydrolysis at high acidity, and complicated procedures. Such shortcomings have limited their applications in chemically modified electrodes. ${ }^{17}$ Therefore, some non-silica sol-gel materials are desired for preparation of chemically modified electrodes. Titania is a kind of non-silica material easily obtained from the sol-gel process..$^{22-24}$ In recent years, a

$\dagger$ To whom correspondence should be addressed.

E-mail: rpliang@ncu.edu.cn titania sol-gel material prepared by a new vapor deposition method has been developed. ${ }^{25-27}$ This method simplified the procedure of sol-gel synthesis, shortened the time in electrode preparation and also avoided the shortcomings caused by acidic catalyst and a calcination step needed in the traditional titania sol-gel process. ${ }^{28-30}$ Compared with other sol-gel immobilization matrices, titania has good biocompatibility. Moreover, titanium has coordination with amine and carboxyl groups on the surface of the enzyme. ${ }^{31}$ These are beneficial for immobilization of the enzyme and maintenance of its bioactivity. Therefore, titania is an available alternative substrate to immobilize the enzyme. ${ }^{32,33}$ $\mathrm{Yu}$ et al. introduced an amperometric glucose sensor, using ferrocenium as a mediator, and $300 \mathrm{mV}$ was selected as the working potential for amperometric detection of glucose. ${ }^{25-27}$ However, the high positive working potentials required might lead to interferences from reducing species such as ascorbic acid (AA), uric acid (UA) and acetaminophen. This drawback can be circumvented with electrocatalysts that allow monitoring $\mathrm{H}_{2} \mathrm{O}_{2}$ at lower potentials.

Prussian blue (PB), as the "artifical peroxidase", is a superior and selective electrocatalyst for $\mathrm{H}_{2} \mathrm{O}_{2}$ reduction ${ }^{34}$ even in the presence of oxygen. ${ }^{35-38}$ Since this catalytic reaction occurs in a relative low potential region, interferences from the coexisting substances such as AA and UA are negligible. A large number of oxidase enzyme-based biosensors for clinical, environmental and food analysis can be obtained by initially electrodepositing $\mathrm{PB}$, followed by immobilizing oxidase enzyme. ${ }^{39-43}$ However, it has been reported that the PB-modified electrode would be disrupted after a few scans at neutral $\mathrm{pH},{ }^{44,45}$ which limited its use in biosensor fabrication. Adding protective films may be an effective method to increase the operational stability. ${ }^{38}$ Ricci et al. have reported an improvement in PB stability, even in alkaline media, when PB was chemically deposited on the surface of a screen-printed carbon electrode (SPCE) in the presence of $\mathrm{KCl}^{36,46}$ Instead of SPCE, screen-printed $\mathrm{Au}$ and $\mathrm{Pt}$ electrodes modified with electrochemically deposited PB have 
been developed and used as the basis for construction of amperometric glucose biosensors through further modification with enzymes immobilized in a Nafion membrane. ${ }^{47}$ Bharathi et al. demonstrated the feasibility of a dual optical/electrochemical mode of measurements using single-pass optically transparent PB electrodes modified by doped PB within the inorganic silicate matrix through the interconnected porous structure of the silicate film. ${ }^{48}$

In this paper, we use a simple and controllable vapor deposition method to prepare a novel GOD-entrapped titania sol-gel film onto the surface of PB-modified gold electrode. The designed GOD/titania sol-gel/PB membrane systems could provide a biocompatible support for enzyme molecules to efficiently retain their good activity and an opportunity for construction of a sensitive amperometric glucose biosensor. The fabricated biosensor showed good performances, such as high sensitivity, improved stability, good selectivity, short response time and a wide linear range owing to the synergic effects of catalysis characters of PB and the GOD molecules, which were immobilized in the titania sol-gel matrix by the vapor deposition method.

\section{Experimental}

\section{Reagents and chemicals}

Glucose oxidase (EC 1.1.3.4, $185000 \mathrm{U} \mathrm{g}^{-1}$, Type II from Aspergillus niger) and poly(diallyldimethylammonium)(PDDA) were purchased from Sigma and used as received. Titanium $n$-butoxide $\left(\mathrm{Ti}(\mathrm{OBu})_{4}, 97 \%\right)$ was obtained from Aldrich. All other chemicals were of analytical grade and were used without further purification. All solutions were made up with doubly distilled water.

\section{Apparatus}

An Autolab PGSTAT30 (Eco Chemie) electrochemical system driven by GPES 4.9 software was used to collect electrochemical data. Electrochemical experiments were performed in a conventional three-electrode system with the enzyme electrode as working electrode, a platinum wire as the auxiliary electrode and an $\mathrm{Ag} / \mathrm{AgCl}(3 \mathrm{M} \mathrm{KCl})$ as reference. Cyclic voltammetric experiments were carried out in a static electrochemical cell at $25^{\circ} \mathrm{C}$, while amperometric experiments were carried out in a stirred cell with a successive addition of glucose standard solution to the solution by applying a potential step of $0.1 \mathrm{~V}$ to the enzyme electrode.

\section{Preparation of Prussian blue electrode}

Prior to modification, gold electrodes (diameter of $2 \mathrm{~mm}$ ) were polished with $1.0,0.3$ and $0.05 \mathrm{~mm}$ alumina slurry $(\mathrm{CH}$ Instruments, Inc.), respectively, and rinsed thoroughly with doubly distilled water between each polishing step. The electrodes were then successively sonicated in 1:1 nitric acid, acetone and doubly distilled water, and then allowed to dry at room temperature. PB film was electropolymerized by cyclic voltammetry in an unstirred fresh combination of $1.0 \mathrm{mM}$ $\mathrm{K}_{3} \mathrm{Fe}(\mathrm{CN})_{6}+1.0 \mathrm{mM} \mathrm{FeCl}_{3} \cdot 6 \mathrm{H}_{2} \mathrm{O}$ in $0.1 \mathrm{M} \mathrm{KCl}+0.1 \mathrm{M} \mathrm{HCl}$ aqueous solution in the potential range of 0.2 to $0.8 \mathrm{~V}$ at a scan rate of $50 \mathrm{mV} \mathrm{s}^{-1}$ for 10 cycles. After deposition, the modified electrodes were rinsed with water $(\mathrm{pH} \mathrm{5.3),} \mathrm{and} \mathrm{the} \mathrm{PB}$ films were activated in a solution containing $0.1 \mathrm{M} \mathrm{KCl}+0.1 \mathrm{M} \mathrm{HCl}$, by cycling the applied potential in a range of -0.05 to $+0.35 \mathrm{~V}$ at a sweep rate of $50 \mathrm{mV} \mathrm{s}^{-1}$ until a stable voltammogram was obtained. After activation, the resulting film was thoroughly rinsed with water (pH 6.0) and dried.

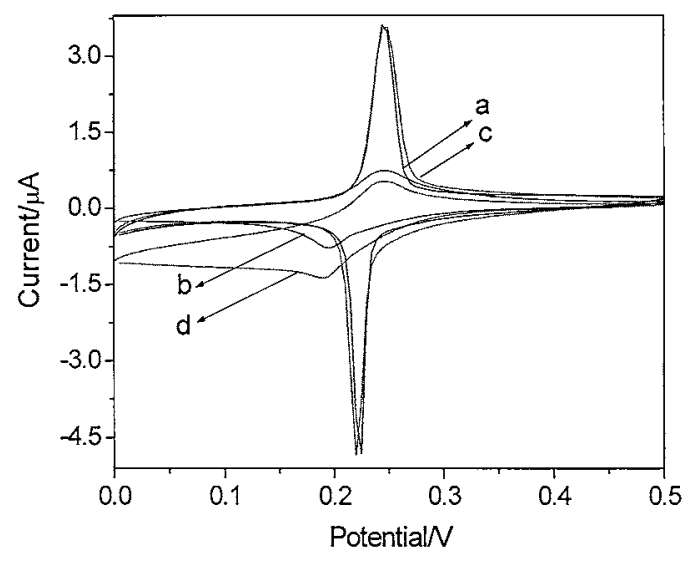

Fig. 1 Cyclic voltammograms of PB film electrode in (a) absence and (c) presence of $3.0 \mathrm{mM}$ glucose, and GOD/titania sol-gel/PB film electrode in (b) absence and (d) presence of $3.0 \mathrm{mM}$ glucose.

\section{Preparation of enzyme electrode}

Titania sol-gel and GOD/titania membranes were prepared as described previously. ${ }^{27}$ A GOD solution was first obtained by dissolving $4.0 \mathrm{mg}$ GOD in $1.0 \mathrm{~mL} 0.02 \mathrm{M} \mathrm{pH} 7.0$ PBS. PBS or $10 \mu \mathrm{L}$ GOD solution (7.4 U GOD) was dropped onto the surface of a PB electrode, which was first immersed in a PDDA solution ( $2 \mathrm{mg} \mathrm{mL}^{-1}$ ) for $20 \mathrm{~min}$ to adsorb a PDDA underlayer. The electrode was then suspended vertically above titanium $n$-butoxide in a sealed flask kept at $25^{\circ} \mathrm{C}$ for $6 \mathrm{~h}$. This resulted in absorption of saturate titanium $n$-butoxide vapor by the solution and slow formation of a titania sol-gel or GOD/titania sol-gel membrane through hydrolysis of titanium $n$-butoxide on the surface. Prior to electrochemical experiments, the GOD/titania sol-gel/PB film electrode was rinsed thoroughly with doubly distilled water and kept in PBS at $4^{\circ} \mathrm{C}$.

\section{Results and Discussion}

\section{Cyclic voltammetric behavior of enzyme electrode}

Figure 1 shows the CVs of the PB electrode and GOD/titania sol-gel/PB film electrode in the absence and presence of glucose in $0.06 \mathrm{M}$ PBS ( $\mathrm{pH} 7.0$, containing $0.1 \mathrm{M} \mathrm{KCl}$ ) solution. In the absence of glucose, the reversible electrochemical behavior of PB was observed on the PB electrode (Fig. 1, curve a). the sharp peak current indicated a regular structure of the inorganic polycrystal. ${ }^{41}$ The waveform with a $\Delta E_{\mathrm{p}}$ around $23 \mathrm{mV}$ indicated the rapid electrochemistry of the immobilized redox active PB. ${ }^{41}$ However, the PB/Prussian White (PW) peaks became broader, the peak separation value increased (around $51 \mathrm{mV}$ ) and the peak current decreased when the GOD/titania sol-gel film was on its surface (Fig. 1, curve b). It may be that the hybrid film causes the mass transfer resistance between the electrode and the electrodeposited layer of PB, and influences the cations crossing the film-solution interface during the oxidation-reduction process. ${ }^{49}$ On addition of $3 \mathrm{mM}$ glucose, nearly no response of the PB electrode is observed (Fig. 1, curve c). However, the reduction peak current increased dramatically and the oxidation current decreased on the GOD/titania sol-gel/ PB film electrode after adding $3 \mathrm{mM}$ glucose into PBS (Fig. 1, curve d), which clearly showed the catalytic properties of modified electrode to the reduction of $\mathrm{H}_{2} \mathrm{O}_{2}$. The detailed catalytic reaction process was as follows: 


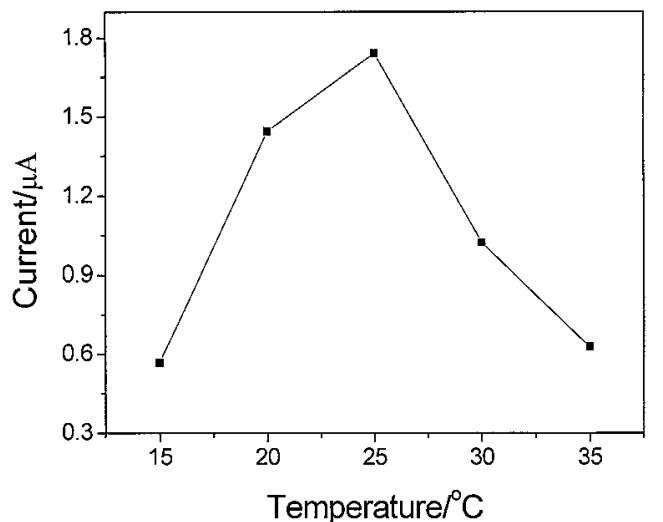

Fig. 2 Effect of temperature for sol-gel film preparation on cathodic peak current of the GOD electrode in $5.0 \mathrm{mM}$ glucose.

$$
\begin{aligned}
& \mathrm{GOD}(\mathrm{FAD})+\beta \text {-D-glucose } \rightarrow \mathrm{GOD}\left(\mathrm{FADH}_{2}\right)+ \\
& \delta \text {-gluconolactone } \\
& \mathrm{GOD}\left(\mathrm{FADH}_{2}\right)+\mathrm{O}_{2} \rightarrow \mathrm{GOD}(\mathrm{FAD})+\mathrm{H}_{2} \mathrm{O}_{2} \\
& \mathrm{Fe}_{4}\left[\mathrm{Fe}(\mathrm{CN})_{6}\right]_{3}+4 \mathrm{e}^{-}+4 \mathrm{~K}^{+} \rightarrow \mathrm{Fe}_{4} \mathrm{~K}_{4}\left[\mathrm{Fe}(\mathrm{CN})_{6}\right]_{3} \\
& \mathrm{~PB} \quad \mathrm{PW} \\
& \mathrm{Fe}_{4} \mathrm{~K}_{4}\left[\mathrm{Fe}(\mathrm{CN})_{6}\right]_{3}+2 \mathrm{H}_{2} \mathrm{O}_{2} \rightarrow \mathrm{Fe}_{4}\left[\mathrm{Fe}(\mathrm{CN})_{6}\right]_{3}+4 \mathrm{OH}^{-}+4 \mathrm{~K}^{+}
\end{aligned}
$$

Glucose diffuses from the bulk solution to the enzyme film, where it is enzymatically oxidized to form gluconate and $\mathrm{H}_{2} \mathrm{O}_{2}$ (Eqs. (1), (2)). The $\mathrm{H}_{2} \mathrm{O}_{2}$ generated is then catalytically reduced by the PW (reduction state of the PB (Eq. (3)), and at the same time the PW is oxidized to PB (Eq. (4)). PB itself is in turn electrochemically reduced to PW under the applied potential (Eq. (3)). The whole process is very rapid. These results indicate that PB can effectively catalyze the glucose oxidation, which is consistent with the results of previous studies of PB-based electrodes. ${ }^{41}$

\section{Optimization of enzyme electrode preparation}

Titanium $n$-butoxide is much more active to water than tetraethyl orthosilicate. In the case of touching with water, the precipitate of titanium dioxide forms immediately. So vapor deposition method is engaged to make the hydrolysis process slow down enough to form a sol-gel but not titanium dioxide powder. The performance of the enzyme electrode mainly depends on the preparation temperature and the amount of enzyme dropped on the electrode surface. ${ }^{25}$

The temperature value directly determines the vapor pressure of titanium $n$-butoxide, which controls the hydrolysis rate. Figure 2 shows the effect of the electrode preparation temperature on the reduction peak current $\left(i_{\mathrm{p}, \mathrm{c}}\right)$. The experiments show that the enzyme electrode gets the best performance at the preparation temperature of $25^{\circ} \mathrm{C}$, at which the rate matches water volatilization rate and results in the largest loading of GOD. Too high temperature results in the formation of titanium dioxide powder on the electrode surface due to a high vapor pressure and a rapid hydrolysis rate of titanium isopropoxide. A low temperature results in a very slow gas deposition rate, which can not catch up with the rate of water volatilization. This brings on a poor yield of the hydrolysis product of titania sol-gel.

The amount of enzyme is an important parameter in the

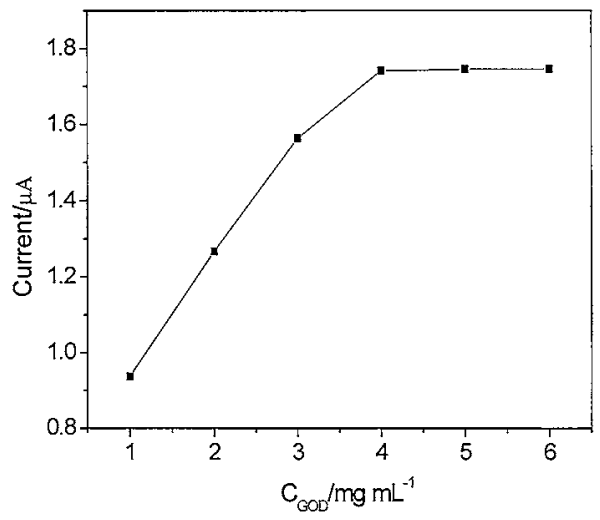

Fig. 3 Effect of enzyme concentration for sol-gel film preparation on cathodic peak current of the GOD electrode in $5.0 \mathrm{mM}$ glucose.

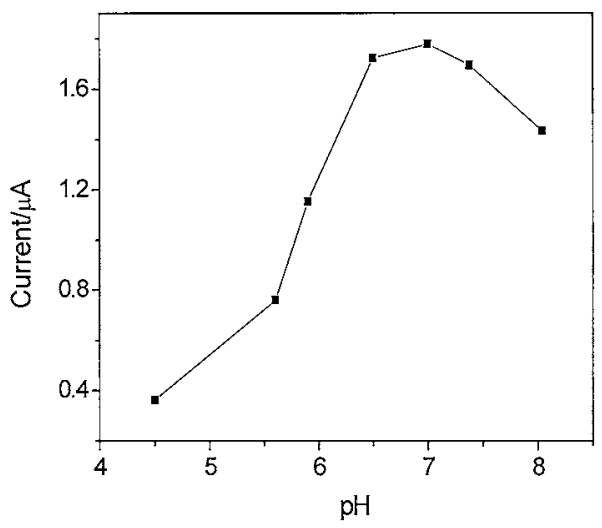

Fig. 4 Effect of $\mathrm{pH}$ on the response of the biosensor to $5.0 \mathrm{mM}$ glucose.

preparation of enzyme electrode. Figure 3 shows the effect of enzyme amount on the $i_{\mathrm{p}, \mathrm{c}}$ of the enzyme electrode. The amperometric response to glucose increases with an increasing concentration of enzyme and reaches a plateau at an enzyme concentration of $4.0 \mathrm{mg} \mathrm{mL}^{-1}$. This indicates that GOD has been saturated on the titania sol-gel/PB thin film. A larger amount of GOD leads to worse compatibility of sol-gel/PB membrane. When the amount of GOD is larger than saturation of sol-gel/PB film, a repulsion effect is produced among superfluous GOD molecules. The stability of GOD/titania solgel/PB membrane is thus debased and the GOD molecules tend to fall off easily. And also, solutions of $4.0 \mathrm{mg} \mathrm{mL}^{-1} \mathrm{GOD}$ were adopted for electrode immobilization.

\section{Condition optimization for glucose sensing}

Various experimental parameters which affect the amperometric determination of glucose, such as the $\mathrm{pH}$ of the solution and applied potential, were studied.

Because the bioactivity of GOD and the stability of $\mathrm{PB}$ are $\mathrm{pH}$-dependent, the influence of buffer $\mathrm{pH}$ is very essential to the sensitivity of the biosensors. ${ }^{38,43}$ For example, a strong acidic solution will decrease the bioactivity of the enzyme; and an alkaline solution will decrease both the stability of PB and the bioactivity of GOD. These effects will lead to an obvious decrease in response of the sensor. Figure 4 shows the effect of the $\mathrm{pH}$ value of the detection solution on the performance of the biosensor. The optimum response was achieved in the $\mathrm{pH}$ range 


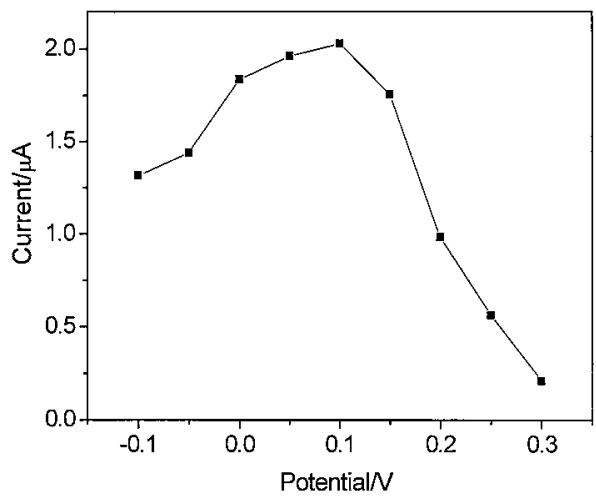

Fig. 5 Effect of applied potential on amperometric response of biosensor in $5.0 \mathrm{mM}$ glucose.

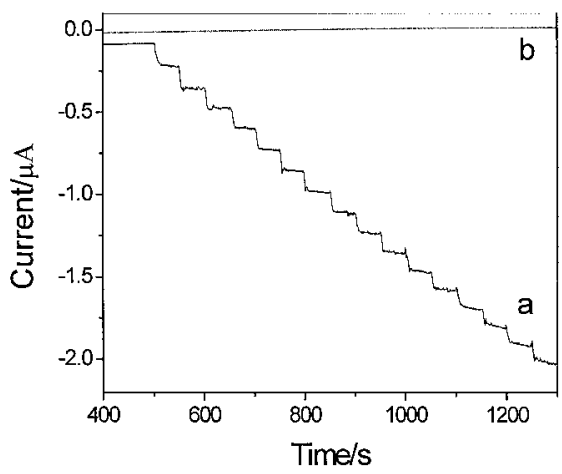

Fig. 6 Amperometric responses of (a) GOD/titania sol-gel/PB film and (b) titania monolayer film electrodes at $0.1 \mathrm{~V}$ in $\mathrm{pH}$ 7.0 PBS with injecting an increment of $300 \mu \mathrm{M}$ glucose every $50 \mathrm{~s}$.

$6.5-7.5$, which is close to the optimum $\mathrm{pH} 7.0$ observed for free GOD and near the physiological environment. This is in good agreement with results reported previously.50,51 To ensure higher sensitivity and stability of the biosensor, we chose a 0.06 M PBS ( $\mathrm{pH} 7.0$, containing $0.1 \mathrm{M} \mathrm{KCl}$ ) for the determination of glucose.

The amperometric response of the sensor depends on the applying potential. The effect of the working potential on the amperometric response of the biosensor was studied between -0.1 and $+0.3 \mathrm{~V}$. The result is shown in Fig. 5. The maximum response was reached at $0.1 \mathrm{~V}$ and it was selected as the working potential. This result was superior to those of the previous studies. ${ }^{36,52,53}$

\section{Amperometric response and calibration curve}

Figure 6a shows a typical current-time plot for the sensor at $0.1 \mathrm{~V}$ on successive addition of $300 \mu \mathrm{M}$ glucose in $0.06 \mathrm{M} \mathrm{pH}$ 7.0 PBS. When an aliquot of glucose is added into the buffer solution, the reduction current rises steeply to reach a stable value as a result of the reduction of $\mathrm{H}_{2} \mathrm{O}_{2}$ produced from enzymatic reaction, while direct catalysis of glucose is not observed at blank titania sol-gel film electrode in the studied potential window (Fig. 6b). The sensor achieves $95 \%$ of steadystate current in less than $10 \mathrm{~s}$. The response rate is much faster than that of $50 \mathrm{~s}$ reported in the pure silica sol-gel matrix, ${ }^{20} 30 \mathrm{~s}$ in PB modified $\mathrm{SPE}^{46}$ and $20 \mathrm{~s}$ in copolymer grafting silica solgel membrane. ${ }^{21}$ Such a short response time further proves that the vapor deposition-derived titania sol-gel material is a

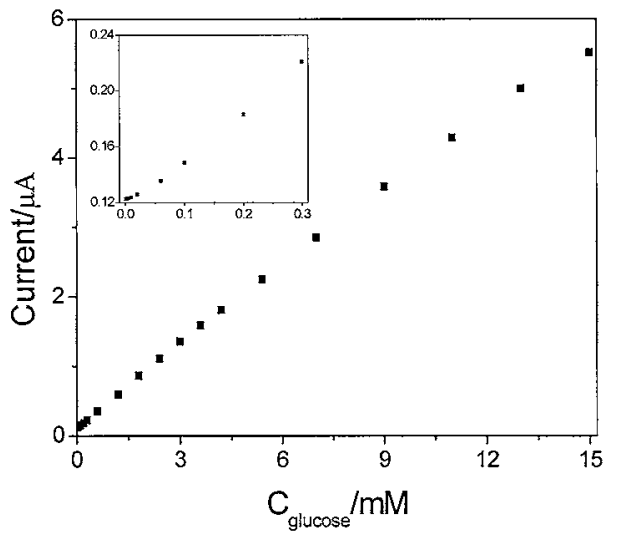

Fig. 7 Glucose calibration curve obtained with GOD/titania sol-gel/ PB modified electrode. In the lower insert, the response curve for glucose additions is also shown.

promising platform for the construction of biosensors..$^{25}$

The calibration curve of the sensor under the optimized conditions shows a linear range from 0.02 to $15 \mathrm{mM}$ for glucose response with a detection limit of $5 \mu \mathrm{M}(S / N=3)$. The sensitivity is $12.74 \mu \mathrm{A} \mathrm{cm}^{-2} \mathrm{mM}^{-1}$ (Fig. 7), which is 1.77 times that reported for glucose sensor based on vapor depositionderived titania sol-gel material with ferrocenium as a mediator, ${ }^{27}$ and higher than those of $6.25,,^{54} 5.2,,^{55} 6.91,{ }^{56} 1.7^{57}$ and $0.28 \mu \mathrm{A}$ $\mathrm{cm}^{-2} \mathrm{mM}^{-1} .58$ The present method for the fabrication of the GOD/titania sol-gel/PB film biosensor is enzyme-friendly for maintaining the enzyme activity and highly useful for preventing the enzyme leakage. In addition, $\mathrm{PB}$ can catalyze the electrochemical reduction of $\mathrm{H}_{2} \mathrm{O}_{2}$ formed from the GOD catalytic oxidation of glucose and can act as an electron-transfer mediator between the electrode and $\mathrm{H}_{2} \mathrm{O}_{2}$, resulting in enhanced detection sensitivity.

\section{Interferences}

In order to study the selectivity of the glucose biosensor, we examined the response of the biosensor in the presence of different concentration interferences with glucose concentration of $0.1 \mathrm{mM}$. In the presence of AA $(0.1 \mathrm{mM})$, the response of the biosensor decreased only about $3 \%$, while in the presence of UA $(0.1 \mathrm{mM})$ and cysteine $(0.01 \mathrm{mM})$, the current increased 0.2 and $1.2 \%$, respectively. Our results indicated that the obtained biosensor has good anti-interferent ability, which is attributed to the lower detection potential due to the synergic catalysis effects of PB and the GOD molecules.

\section{Reproducibility and stability of the sensor}

The relative standard deviation (RSD) of five successive measurements to $0.1 \mathrm{mM}$ glucose was $1.3 \%$, and the RSD of 10 biosensors for detection of $0.1 \mathrm{mM}$ glucose was $2.3 \%$ for the inter-electrode repeatability, which indicated that the sensor has a good reproducibility for glucose sensing. The stability of the sensor was evaluated by a lifetime experiment. The sensor was used for $3 \mathrm{~h}$ each day and the calibration plots involving $n=7$ glucose determinations were carried out at hourly intervals. The sensor was stored at $4^{\circ} \mathrm{C}$ after use. The means of daily values of slopes were compared. The results showed that the slope at the fifth day is $96 \%$ of that at the first day. After 2 weeks, the slope only declined to $91 \%$ and the half-life period of these enzyme sensors was about 3 months. This further demonstrates that titania sol-gel/PB film is very efficient for retaining the enzyme activity and allows the biosensor to keep a long lifetime. Good 
reproducibility and long-term stability can be attributed to two aspects. First, large quantities of hydroxyl groups in titania solgel hybrid material can form strong hydrogen bonds with the enzyme molecules, which prevent the enzyme from leaking out of the film. ${ }^{18}$ Second, the immobilization does not become involved in the chemical modification of the enzyme molecules and provides a biocompatible microenvironment around the enzyme molecules to stabilize its biological activity, which maintains the biological activity of enzymes to a large extent. ${ }^{19,27}$

\section{Conclusions}

We have fabricated an amperometric glucose biosensor based on titania sol-gel/PB composite film by vapor deposition method. The proposed titania sol-gel/PB composite film is highly useful for the bioelectrochemical/biosensing applications, and possesses excellent catalytic, high surface area, good mechanical stability and biocompatible properties. Thus the film provides a compatible microenvironment for maintaining the activity of the immobilized enzyme, and more importantly prevents the leakage of enzyme. The designed GOD/titania sol-gel/PB composite film biosensor exhibits a high affinity to glucose, and a variety of good performance characteristics such as high sensitivity, fast response, low interference, acceptable reproducibility and longterm stability. In addition, this report offered an effective means for preparing three dimensional titania sol-gel biocompatible interfaces, which would facilitate the use of biosensors for more widespread applications.

\section{Acknowledgements}

This work was supported by grants from the National Natural Science Foundation of China (NSFC, No. 20605010), the Jiangxi Province Natural Science Foundation (JXNSF, Nos. 0520075, 0620039, 2007JZH2644), the Opening Foundation of State Key Laboratory of Chem/Biosensing and Chemometrics of Hunan University (SKLCBC, No. 2007012) and the Jiangxi Province Education Office (GJJ08017).

\section{References}

1. J. Chen, J. H. Tang, F. Yan, and H. X. Ju, Biomaterials, 2006, 27, 2313.

2. G. Y. Shi, Z. Y. Sun, M. C. Liu, L. Zhang, Y. Liu, Y. H. Qu, and L. T. Jin, Anal. Chem., 2007, 79, 3581.

3. H. Ohnuki, T. Saiki, A. Kusakari, H. Endo, M. Ichihara, and M. Izumi, Langmuir, 2007, 23, 4675.

4. G. X. Wang, H. Y. Lu, and N. F. Hu, J. Electroanal. Chem., 2007, 599, 91 .

5. Y. C. Li, W. F. Bu, L. X. Wu, and C. Q. Sun, Sens. Actuators, B, 2005, 107, 921.

6. D. Ivnitski, I. Abdel-Hamid, P. Atanasov, and E. Wilkins, Biosens. Bioelectron., 1999, 14, 599.

7. R. Koncki, A. Hulanicki, and S. Glab, Trends Anal. Chem., 1997, 16, 528.

8. J. K. Kirk and C. C. Rheney, J. Am. Pharm. Assoc., 1998, $38,210$.

9. C. Henry, Anal. Chem., 1998, 70, 594A.

10. J. Wang, Anal. Chem., 1999, 71, 328R.

11. Y. Lvov and H. Möhwald, "Protein Architecture: Interfacing Molecular Assemblies and Immobilization
Biotechnology", 2000, Marcel Dekker, New York.

12. T. Yao and K. Takashima, Biosens. Bioelectron., 1998, 13, 67.

13. A. Navas Diaz, M. C. Ramos Peinado, and M. C. Torijas Minguez, Anal. Chim. Acta, 1998, 363, 221.

14. J. Li, S. N. Tan, and J. T. Oh, J. Electroanal. Chem., 1998, $448,69$.

15. J. Z. Zhang, B. Li, Z. X. Wang, G. J. Cheng, and S. J. Dong, Anal. Chim. Acta, 1999, 388, 71.

16. B. C. Dave, B. Dunn, J. S. Valentine, and J. I. Zink, Anal. Chem., 1994, 66, 1120A.

17. O. Lev, M. Tsionsky, L. Rabinovich, V. Glezer, S. Sampath, I. Pankratov, and J. Gun, Anal. Chem., 1995, 67, 22A.

18. J. Wang, Anal. Chim. Acta, 1999, 399, 21.

19. Q. Chen, G. L. Kenausis, and A. Heller, J. Am. Chem. Soc., 1998, 120, 4582 .

20. J. Li, L. S. Chia, N. K. Goh, and S. N. Tan, Anal. Chim. Acta, 1998, 362, 203.

21. B. Wang, J. Zhang, and S. Dong, Biosens. Bioelectron., 2000, 15, 397.

22. O. Harizanov and A. Harizanova, Sol. Energy Mater. Sol. Cells, 2000, 63, 185.

23. M. P. Zheng, M. Y. Gu, Y. P. Jin, H. H. Wang, P. F. Zu, T. Tao, and J. B. He, Mat. Sci. Eng., B, 2001, 87, 197.

24. H. Lin, H. Kozuka, and T. Yoko, Thin Solid Films, 1998, $315,111$.

25. J. H. Yu and H. X. Ju, Anal. Chem., 2002, 74, 3579.

26. J. H. Yu and H. X. Ju, Anal. Chim. Acta, 2003, 486, 209.

27. J. H. Yu, S. Q. Liu, and H. X. Ju, Biosens. Bioelectron., 2003, 19, 401.

28. Z. T. Jiang and Y. M. Zuo, Anal. Chem., 2001, 73, 686.

29. T. López, J. Hernandez-Ventura, R. Gómez, F. Tzompantzi, E. Sánchez, X. Bokhimi, and A. García, J. Mol. Catal. A, 2001, 167, 101

30. E. Milella, F. Cosentino, A. Licciulli, and C. Massaro, Biomaterials, 2001, 22, 1425.

31. Y. Kurokawa, T. Sano, H. Ohta, and Y. Nakagawa, Biotechnol. Bioeng., 1993, 42, 394.

32. J. F. Kennedy and I. M. Kay, J. Chem. Soc. Perkin Trans., 1976, $1,329$.

33. Q. Li, G. Luo, J. Feng, Q. Zhou, L. Zhang, and Y. Zhu, Electroanalysis, 2001, 13, 413.

34. A. A. Karyakin, E. A. Puganova, I. A. Budashov, I. N. Kurochkin, E. E. Karyakina, V. A. Levchenko, V. N. Matveyenko, and S. D. Varfolomeyev, Anal. Chem., 2004, 76,474 .

35. A. A. Karyakin, O. V. Gitelmacher, and E. E. Karyakina, Anal. Lett., 1994, 27, 2861.

36. F. Ricci, A. Amine, C. S. Tuta, A. A. Ciucu, F. Lucarelli, G. Palleschi, and D. Moscone, Anal. Chim. Acta, 2003, 485, 111.

37. B. Haghighi, S. Varma, F. M. Alizadeh Sh, Y. Yigzaw, and L. Gorton, Talanta, 2004, 64, 3.

38. F. Ricci and G. Palleschi, Biosens. Bioelectron., 2005, 21, 389.

39. A. A. Karyakin, E. E. Karyakina, and L. Gorton, Talanta, 1996, 43, 1597.

40. A. A. Karyakin, O. V. Gitelmacher, and E. E. Karyakina, Anal. Chem., 1995, 67, 2419.

41. A. A. Karyakin and E. E. Karyakina, Sens. Actuators, B, 1999, 57, 268.

42. I. L. de Mattos, L. V. Lukachova, L. Gorton, T. Laurell, and A. A. Karyakin, Talanta, 2001, 54, 963.

43. J. D. Qiu, H. Z. Peng, R. P. Liang, J. Li, and X. H. Xia, Langmuir, 2007, 23, 2133.

44. R. Garjonyte and A. Malinauskas, Sens. Actuators, B, 1999, 
$56,93$.

45. I. L. de Mattos and M. C. D. Areias, Talanta, 2005, 66, 1281.

46. F. Ricci, A. Amine, G. Palleschi, and D. Moscone, Biosens. Bioelectron., 2003, 18, 165.

47. I. L. de Mattos, L. Gorton, T. Laurell, A. Malinauskas, and A. A. Karyakin, Talanta, 2000, 52, 791.

48. S. Bharathi and O. Lev, Appl. Biochem. Biotechnol., 2000, 89, 209.

49. K. Itaya, I. Uchida, and V. D. Neff, Acc. Chem. Res., 1986 19, 162.

50. D. Zhang, K. Zhang, Y. L. Yao, X. H. Xia, and H. Y. Chen, Langmuir, 2004, 20, 7303.

51. W. Zhao, J. J. Xu, C. G. Shi, and H. Y. Chen, Langmuir 2005, 21, 9630.
52. Y. J. Zou, L. X. Sun, and F. Xu, Biosens. Bioelectron., 2007, 22, 2669.

53. I. L. de Mattos, L. Gorton, and T. Ruzgas, Biosens. Bioelectron., 2003, 18, 193.

54. T. J. Ohara, R. Rajagopalan, and A. Heller, Anal. Chem., 1993, 65, 3512 .

55. T. J. Ohara, R. Rajagopalan, and A. Heller, Anal. Chem., 1994, 66, 2451.

56. E. Csöregi, C. P. Quinn, D. W. Schmidtke, S. Lindquist, M. V. Pishko, L. Ye, I. Katakis, J. A. Hubbell, and A. Heller, Anal. Chem., 1994, 66, 3131.

57. T. de Lumley-Woodyear, P. Rocca, J. Lindsay, Y. Dror, A. Freeman, and A. A. Heller, Anal. Chem., 1995, 67, 1332.

58. J. C. Vidal, E. Garcia, and J. R. Castillo, Biosens. Bioelectron., 1998, 13, 371. 